\title{
NOTAS
}

\section{Tres Antologías de Teatro}

Carlos Solórzano, a quien se debe una de las pocas antologías generales de teatro hispanoamericano aparecidas hasta el momento - limitada, de propósito, a la producción dramática del pasado cuarto de siglo- ${ }^{1}$ of rece ahora una obra semejante (Teatro breve bispanoamericano contemporánes, Selección, prólogo y notas por Carlos Solórzano, Madrid, Aguilar, 1970), esta vez colección de piezas en un acto. ${ }^{2}$ El criterio para la selección de su material parece haber sido, por una parte, de restricción cronológica - los últimos veinticinco años, como la antología anterior- $-y$, por otra, de alcance panorámico. La intención de ceñirse en forma estricta al periodo más reciente justificaría la exclusión, de otro modo inexpli: cable, de Xavier Villaurrutia, dramaturgo que cultivó el teatro en un acto con singular talento. En cuanto al plazo de los últimos veinticinco años, si bien es cierto que a él corresponde el verdadero desarrollo del teatro, largo o breve, en Hispanoamérica, yerra Solórzano al conferir en su prólogo a dicho período la mayor importancia en la evolución europea de la pieza en un acto como género "independiente". Solórzano parece olvidar el papel destacado que tuvo la obra breve en los movimientos renovadores de fines del siglo pasado y principios del presente —el Teatro Libre, el teatro simbolista y Lugné-Pöe, el Abbey Theaker de Dublíny las obras maestras en un acto de Maeterlinck, Synge, Strindberg, Piran-

${ }^{1}$ El teatro bispanoamericano contemporáneo. México-Buenos Aires, 1964, ed. Fondo de Cultura Económica. (No incluye a autores mexicanos, por haber dedicado a ellos otros tomos el Fondo de Cultura Económica, según aclara Solórzano en el prólogo).

2 José Miguel Oviedo ha escrito ya una nota sobre este libro, publicada en la Revista Iberoamericana (Nos. 76-77, julio-diciembre de 1971), cue no conocía yo al redactar la mía. Después de dudar bastante sobre la supresión de esta parte de mi artículo, me he decidido por dejarla, ya que, aunque mis comentarios son más generales, toco algún que otro punto diferente o veo ciertas cosas desde otro ángulo. No comparto, por ejemplo, el pesimismo de Oviedo sobre el curso futuro de nuestra literatura dramática y de mis esperanzas ( $\mathrm{y}$ razones para ellas) hablo en el presente trabajo. Por otra parte, coincido con él en casi todos los juicios que formula sobre las obras incluidas en la antología de Solórzano y remito al lector a su agudo examen. 
dello, O'Neill, Valle-Inclán, Ghelderode, García Lorca ..., todas anteriores a la segunda guerra mundial.

La visión panorámica que ha presidido la compilación, permite - lo cual es, desde cierto punto de vista, una virtud- que estén representados en ella casi todos los países hispanoamericanos, pero adolece del defecto consiguiente, la desigualdad cualitativa. Las razones de esta desigualdad no escapan a nadic medianamente enterado: en las áreas de Hispanoamérica con más larga e intensa actividad teatral durante el presente siglo, los "productos" de la literatura dramática han sido, obviamente, más abundantes y logrados. Lo cual no invalida, claro está, la posibilidad de nuevos desarrollos: de hecho, ya se insinúan aquí y allá.

Varias piezas valiosas compensan, por otra parte, las debilidades del tomo; a fin de cuentas, escasean las ediciones generalmente accesibles de esas obras y esta antología es medio adecuado para su difusión. (Queda aún mucho camino por recorter en cuanto a la divulgación del buen teatro hispanoamericano del día). Sobresalen "Historia del hombre que se convirtió en perro", de Osvaldo Dragún, la última de sus "Historias para ser contadas" - farsa crítica social, de agria e ingeniosa comicidad-:; "Las pinzas", de Román Chalbaud -pieza que por medio de juegos rituales a la Jean Genet, revela insuficiencias "originales" del hombre, cuyos valores son vistos bajo el aspecto del sinsentido, como en gran parte del teatro de hoy- y "Los fantoches", de Solórzano mismo, pequeño teatro del mundo donde los hombres-muñecos buscan, angustiados, respuestas al enigma de la existencia. Se echa de menos la presencia del chileno Jorge Díaz, posiblemente el autor teatral más brillante de los últimos diez años en Hispanoamérica, pero Díaz me aclaró en una conversación reciente que la obra suya destinada a la antología no había pasado la censura (riesgo que se corre al publicar en España y que ya, por rutinario, no provoca indignación). Me hubiera satisfecho más encontrar obras, sin duda superiores, de Virgilio Piñera y de Elena Garro - "Falsa alarma" del primero y "Un hogar sólido", de la segunda-, pero es probable que ambos autores decidieran contribuir al volumen con las piezas incluidas, privando así al antólogo de la facultad de elección.

En fin, es alentador comprobar - y esta antología es índice de elloque el entusiasmo por el arte del teatro en Hispanoamérica está más vivo y extendido que nunca. $Y$ no hay que olvidar que a dicho entusiasmo, traducido en actividad creadora por numerosos equipos escénicos y los dramaturgos que escriben para ellos, se debe que la lista de obras dramáticas apreciables sea cada día mayor en nuestras literaturas (a pesar, 
o, mejor, a partir de las imperfecciones y tanteos propios de estos procesos de desarrollo).

Una breve antologia de George Woodyard (The Modern Stage in Lalin America: Six Plays, New York, E. P. Dutton and Co., Inc., 1971) da testimonio del creciente interés, aunque data sólo de pocos años, por el teatro iberoamericano en los Estados Unidos. Esta antología es una de las primeras publicadas en inglés con obras de varios autores y la intención de ofrecer una idea del estado actual del teatro en Latinoamérica. Las seis obras recogidas, en traducciones excelentes," son: "Los soles truncos", de René Marqués; "O pagador de promessas", de Alfredo Dias Gomes; "Y nos dijeron que éramos inmortales", de Osvaldo Dragún; "El lugar donde mueren los mamíferos", de Jorge Díaz; "La noche de los asesinos", de José Triana; "Yo también hablo de la rosa", de Emilio Carballido.

Me resulta difícil señalar faltas en una antología que sirve de in. troducción, para el público lector y los teatristas notteamericanos, a un aspecto de nuestra cultura poco conocido fuera de Iberoamérica ( $\mathrm{y}$ no siempre bien dentro de ella). Sin embargo, ciertas cuestiones relacionadas con la presente selección demandan un comentario menos apologético de lo que yo desearía. Si George Woodyard no afirmara en el prólogo, por otra parte buen resumen histórico, que estas piezas se han escogido "como los mejores y más representativos ejemplos de temas y técnicas actuales", mis reparos se habrían atenuado considerablemente. Después de todo, un antólogo escoge siempre a su gusto y creo que éste es su privilegio incontestable. Ahora bien, su juicio concluyente (o excluyente), me obliga a una resuelta discrepancia, que no es, desde luego, absoluta. Cierto que las obras seleccionadas de Dias Gomes, de Díaz y de Triana bien merecen el juicio de Woodyard. La del primero (muy conocida internacionalmente por la cinta cinematográfica basada en ella) es digna muestra de la corriente realista de los últimos años en el teatro iberoamericano. Su asunto, el conflicto existente en Brasil entre dos formas religiosas - una, la del culto católico de la casta portuguesa, otra, la de las prácticas de origen africano-, se desarrolla de manera "ejem. plar" entre personajes típicos de la sociedad brasileña. La muerte del protagonista, víctima de la intolerancia católica ( $u$ oficial) frente a sus creencias, adquiere carácter de sacrificio, dimensión de símbolo, cuando al final es levantado en hombros de la muchedumbre sobre la cruz que

${ }^{3}$ De Richard John Wiezell, Oscar Fernández, Alden James Green, Naomi Wilson, Pablo Armando Fernández-Michael Kustow y William I. Oliver, respectivamente, poi el orden en que nombro las piezas, que es también aquel en que aparecen en la antología. 
traía a la iglesia para cumplir su promesa a Santa Bárbara-Yansán. Tal vez este ennoblecimiento trágico de lo cotidiano (personajes vulgares, ambiente callejero) sea lo más admirable de la obra, que trasciende, así, el nivel del mero drama de costumbres. "El lugar donde mueren los mamíferos", de Jorge Díaz, es una "humorada" —como, hasta ahora, todas sus obras- sobre las organizaciones de asistencia social, o, mejor, contra la deformación de sus fines a manos de los directivos de ellas, a cuya mayor gloria suelen servir y no al mejoramiento de los supuestos beneficiarios. Díaz ha asimilado en forma muy personal el lenguaje del humor negro tan en boga actualmente, pero su arte pertenece, en el fondo, a una rica tradición hispánica del grotesco, de la cual es, por afinidad y natural influencia, continuador (Arcipreste de Hita, Celestina. Quevedo, Goya, Valle-Inclán, Buñuel). "La noche de los asesinos", de José Triana, drama acerca de la lucha -que puede tener la violencia con que la presenta el autor-, de las nuevas generaciones contra las inmediatamente anteriores, salva ciertas inconsistencias con una armazón apropiada para la explotación espectacular. El éxito que ha tenido la puesta en escena de la obra bajo la dirección de Peter Brooks, maestro en montajes de gran artificio, parece confirmar mi impresión.

En cuanto a las otras obras escogidas por Woodyard, no llegan al nivel de excelencia que él atribuye a todas en su prólogo, y existen ya bastantes que podrían haber ocupado sus lugares. "Los soles truncos" es, a todas luces, la más endeble. Está construida a base de recursos ingenuos -efectismo, más bien -y bordea continuamente lo sensiblero. Su simbolismo patriótico, en fin, será loable en el terreno humanitario, no así, por desgracia, en el estético, ya que carece de sutileza, o, en otras palabras, de la proporción de densidad e ironía que da a la literatura "objetivadora", ya sea narrativa o, teatro, categoría de buen arte (sobran, por conocidos, los paradigmas). "Y nos dijeron que éramos inmortales", denuncia de condiciones sociales e instituciones mutiladoras del hombre (rutina de los intereses materiales, inhumano servicio militar), falla no tanto por el simplista desarrollo de su alegato, como por lo mal que se ajusta la línea épica de la pieza al realismo más convencional, nada "alienado", que domina en ella. Una propensión gratuita a lo sentimental subraya, a mi modo de ver, el defecto de composición aludido. El resultado es de una manifiesta incongruencia. "Yo también hablo de la rosa", amalgama de perspectivismo orteguiano y alabanza de las misteriosas fuerzas creadoras del hombre, deja bastante que desear como muestra de Emilio Carballido, dramaturgo que se ha distinguido en otras acasiones por su capacidad para combinar imaginación, sondeo psicoló- 
gico, comentario social y astucia técnica. Esta pieza está lejos de ejemplificar esa virtud. Por el contrario, los diálogos de Polo y Toña, parodias trilladas, con intención de sátira, se repiten hasta el aburrimiento, sin que logren vitalizar la pieza las irrupciones de la realidad cotidiana o de la "mágica" (representada por la medium y el coro), buenos pasajes de la obra. Si el propósito del antólogo fue incluir una pieza reciente de Carballido, elección más acertada habría sido "¡Silencio, pallos pelones, ya les van a echar su maíz!", probablemente su obra maestra hasta el día de hoy.

13 autores del nuevo teatro venezolano (Selección, prólogo y notas de Carlos Miguel Suárez Radillo, Caracas, Monte Avila Editores, 1971) en un muestrario particular, esto es, referido sólo a un país, de la sostenida actividad dramática que, como he anotado antes, se observa en Hispanoamérica desde hace unos quince años. (Los últimos diez han sido especialmente fértiles en Cuba, Chile y Venezuela). ¿El volumen de Carlos Miguel Suárez Radillo recoge obras de los dramaturgos venezolanos más significativos de esa etapa; su selección, aunque esto suene a paradoja, es a la vez generosa y exigente. Resulta claro que el antólogo ha querido dar entrada al mayor número posible de autores con obras estrenadas en los últimos tiempos. Pero también se evidencia que ha espigado sabiamente, con miras a ofrecer lo mejor de cada cosecha, si bien lo mejor a veces no está en sazón completa o es sólo anuncio, promesa de porvenir. Suárez Radillo refleja, ciertamente, en su introducción y notas, no sólo conocimiento amplio del tema, sino criterio de hombre de teatro de buen gusto y larga experiencia. Domina en este "nuevo teatro" la manera expresionista, con preferencia por las manifestaciones del "absurdo" (las influencias de Beckett, de Ionesco, de Genet, son notables).

Paso ojeada a las obras incluidas en la antología, adelantando valo. raciones que considero todavía provisionales (se trata de un primer encuentro) y que establezco en función, más bien, del conjunto del libro. Lo mejor de lo allí recogido me parece "Los ángeles terribles.", de Román Chalbaud, donde la "familia." formada por Zacarias y sus jóvenes acompañantes (Sagrario, Angel, Gabriel), más que un modo de aludir a las complejas relaciones entre los hombres, es una metáfora - viviente, apasionada, no rígida alegoría- para los deseos incumplidos, fantasías, fracasos y crueldades que dominan dolorosamente una zona profunda de la vida humana. "Tric Trac", de Isaac Chocrón es una obra importante, una especie de gran circo del mundo concebido bajo el signo de Beckett; creo que ganaría en calidad, sin embargo, si perdiera algo en 
extensión. "Las tijeras", de Paul Williams, acerca de la imposibilidad de comunicación entre dos seres humanos unidos sólo por el "lazo" convencional del matrimonio, es una buena pieza en un acto, diálogo de continuos malentendidos (con algo del Ionesco de La soprano calva) que Williams maneja con soltura y bastante originalidad; es una lástima que haya apelado a un final melodramático tan poco en consonancia con el tono grotesco del resto de la obra. Se observan aciertos parciales en "Los peces del acuario", vacilante de tema (¿sátira social? ¿ironía sobre las limitaciones congénitas del hombre?), de José Gabriel Núñez, " $1 \times 1=1$, pero $1+1=2$ ", de Lucía Quintero, que juega imaginativamente con las nociones de cordura y locura y "La muerte de Alfredo Gris", de Rodolfo Santana, cuyo protagonista es reo, un poco a la manera del antihéroe de $E l$ proceso, de un delito que ignora, aunque aquí queda claro que se le ejecuta por creerle las autoridades participante en una manifestación popular (con lo cual la obra adquiere sentido concreto de protesta contra un sistema político represivo).

Otras obras son interesantes en líneas generales. Asi, "Catón y Pilato", de Alejandro Lasser, donde se contrastan el hombre público que antepone sus principios éticos a todo y el que acaba por someterse al intetés egoísta, representados ambos por los "históricos" Catón y Pilato. La técnica del entrecruzamiento de las acciones es efectiva para el desarrollo del paralelo entre las dos figuras, si bien se echa de menos una profundización del conflicto interior de cada personaje: éstos parecen conducirse de acuerdo a moldes prefijados de heroicidad sobrehumana e inconsistencia moral. También tiene interés " $\mathrm{La}$ esquina del miedo", de César Rengifo, estudio -de trazos expresionistas algo gruesos- de la cobardía que permite, en muchas ocasiones, que muera un hombre sin el auxilio, tal vez salvador, de sus semejantes.

Menos afortunadas me parecen piezas como "Agua Linda", de Ricardo Acosta, "Fiésole", de José Ignacio Cabrujas, "En el vasto silencio de Manhattan", de Elisa Lerner e "Intervalo" de Elizabeth Schön. Ado. lecen las tres primeras de un excesivo lirismo que les resta vitalidad, dinamismo en sentido dramático. "Agua Linda" es nada más que una alegoría político-social oscurecida por imágenes abigarradas; "Fiésole", decididamente, es un poema a dos voces (es curioso que Cabrujas, actor distinguido, no muestre aquí mucha habilidad escénica y sí dotes poéticas); "En el vasto silencio de Manhattan" tiene personajes que no se definen como tales, pues a todos asigna la autora el mismo, indiferenciado, lenguaje poético: de ahí que los mejores pasajes de la obra sean los monólogos de Rosie, la protagonista --suerte de "última puritana"- 
pues este lenguaje traduce bien su psicología de solterona anhelante y siempre frustrada. "Intervalo" es una obra algo desconcertante. Pertenece a la cateoría de ese teatro poético con rasgos de caricatura que uno aso. cia a los nombres de los belgas Crommelynck y Ghelderode, de Audiberti, de Lorca en "Amor de don Perlimplín...", pero le faltan concisión de lenguaje y profundidad; da la impresión de que la autora se ha entregado a cierta facilidad "imaginista" y a ella ha supeditado lo demás. Por otro Iado, "El hombre de la rata", monólogo de Gilberto Pinto, falla por lo contrario, al caer en el plano del discurso aleccionador para lo que el personaje llama "la lucha por la empresa humana"; la obra, debo añadir en justicia, está bien construida dentro de cierta línea de efectismo teatral, prueba de la habilidad histriónica del autor, que la interpretó en su estreno.

Esta antología debía servir de estímulo a la preparación de obras semejantes de repertorios nacionales escogidos con un mínimo de rigor (algunas ya existentes, de una editorial muy conocida, son incompletas, y deplorables algunos de sus textos). Por el momento se imponen los volúmenes de Cuba y de Argentina, aparte de las puestas al día de otras buenas compilaciones por países. Con el tiempo, espero, irán surgiendo nuevas necesidades.

University of Pitlsburgh

Julio Matas 
